\title{
Year-round pack ice in the Weddell Sea, Antarctica: response and sensitivity to atmospheric and oceanic forcing
}

\author{
Cathleen A. Geiger, ${ }^{1}$ Stephen F. Ackley, ${ }^{2}$ William D. Hibler, III ${ }^{1}$ \\ ${ }^{1}$ Thayer School of Engineering, Dartmouth College, Hanover, NH 037.55, U.S.A. \\ ${ }^{2}$ U. S. Army Cold Regions Research and Engineering Laboratory, 72 Lyme Road, Hanover, NH 03755, U.S.A.
}

\begin{abstract}
Using a dynamic-thermodynamic numerical sea-ice model, external oceanic and atmospheric forcings on sea ice in the Weddell Sea are examined to identify physical processes associated with the seasonal cycle of pack ice, and to identify further the parameters that coupled models need to consider in predicting the response of the pack ice to climate and ocean-circulation changes. In agreement with earlier studies, the primary influence on the winter ice-edge maximum extent is air temperature. Ocean heat flux has more impact on the minimum ice-edge extent and in reducing pack-ice thickness, especially in the eastern Weddell Sea. Low relative humidity enhances ice growth in thin ice and open-water regions, producing a more realistic ice edge along the coastal areas of the western Weddell Sea where dry continental air has an impact. The modeled extent of the Weddell summer pack is equally sensitive to ocean heat flux and atmospheric relative humidity variations with the more dynamic responses being from the atmosphere. Since the atmospheric regime in the eastern Weddell is dominated by marine intrusions from lower latitudes, with high humidity already, it is unlikely that either the moisture transport could be further raised or that it could be significantly lowered because of its distance from the continent (the lower humidity source). Ocean heat-transport variability is shown to lead to overall ice thinning in the model response and is a known feature of the actual system, as evidenced by the occurrence of the Weddell Polynya in the mid 1970s.
\end{abstract}

\section{INTRODUCTION}

Sea ice in the Weddell Sea undergoes a large seasonal cycle, varying from about $2 \times 10^{6} \mathrm{~km}^{2}$ area for the summer minimum to about $8 \times 10^{6} \mathrm{~km}^{2}$ for the winter maximum (Zwally and others, 1983). The summer minimum of the Weddell Sea ice represents about half the area of the pack ice in Antarctica at that time. The Weddell Sea pack ice as a whole is a climatic feature of some importance. Its northern limit $\left(55^{\circ} \mathrm{S}\right.$ latitude) extends well into sub-Antarctic regions and consequently has an influence on the climate, ocean and ecosystems of the South Atlantic region.

Sea-ice cover in the Southern Ocean has been modeled by Parkinson and Washington (1979) using comprehensive atmospheric and oceanic heat flux inputs and ice thermodynamics together with ad hoc sea-ice dynamics. Using more realistic sea-ice dynamics, Hibler and Ackley (1983) examined the dynamic-thermodynamic response of a Weddell Sea sea-ice model focusing on the role of sea-ice processes on the advance and retreat of the ice margin. An important conclusion of that study was that the inclusion of sea-ice dynamics produces a realistic seasonal cycle of sea-ice extent. Following these, a series of ice ocean coupled models (e.g. van Ypersele, 1986; Lemke and others, 1990; Owens and Lemke, 1990; Stössel and others, 1990), and an atmospheric-ice coupled model (Koch, 1988) have also been developed.

Expanding from the results of Hibler and Ackley (1983), we pose the following question: how do specific external (air and occan) forcings affect the ice expansion and decay cycle in the Weddell Sea region? To address this question, we con- sider sensitivity studies of a sea-ice model to the external thermal forcing terms of air temperature, ocean heat flux and relative humidity variations. These three variables, plus solar radiation and cloud cover, comprise the thermal inputs for sea ice. Solar radiation is well defined, has a invariable annual cycle and is included in the model at 6 hour interval averages. Cloud cover can vary widely, is estimated poorly and understood very little.

The three variables examined here fall between being constant (and well defined) and wildly variable (and not understood); they are examined in this paper as a collective. Based on results from a more comprehensive model study (Geiger, 1996), increasing the temporal resolution of the input fields from daily to 6 hour time intervals has a far greater impact on the response of the seasonal cycle of sea ice than does an increase in spatial resolution from 200 to $50 \mathrm{~km}$. This result allows for a considerable reduction in computational time, and enables an efficient series of sensitivity studies. For this reason a relatively low spatial-resolution $(200 \mathrm{~km})$ model with high temporal-input field resolution (4 times a day) is used in the simulations presented here. The sensitivity responses of sea ice to sub-daily atmospheric and radiation forcing conditions presented here have not been well investigated previously. The emphasis of this study is to identify in relative terms how external factors affect sea-ice growth and decay processes. By looking specifically at the response of sea ice to each imposed condition, the intent is to identify the response of the ice prior to the onset of feedback processes to get a first order look at how sea ice reacts to these imposed conditions. 


\section{OVERVIEW OF THE NUMERICAL MODEL}

Numerical sea-ice sensitivity studies were conducted for the Weddell Sea pack ice $\left(80^{\circ} \mathrm{S}-55^{\circ} \mathrm{S}\right.$ by $\left.60^{\circ} \mathrm{W}-20^{\circ} \mathrm{E}\right)$ at $200 \mathrm{~km}$ spatial resolution using the Hibler (1979) dynamicthermodynamic sea-ice model employing a viscous-plastic rheology with pressure relaxed to the origin (Replacement Method in Ip, 1993; Hibler and Ip, 1995). For details of the numerical formulation see Zhang and Hibler (in press) and Geiger (1996). The European Centre for MediumRange Weather Forecasts (ECMWF) air temperature and pressure fields are used as input forcing at 6 hour intervals for 1992 while 1991 fields are used to spin-up the model. Model results are compared to observed ice-edge estimates obtained from satellite analyses conducted by the NavyNational Oceanic and Atmospheric Administration (NOAA) National Ice Center (NIC) as archived at the National Snow and Ice Data Center (NSIDC).

Temporally constant ocean currents were generated from a composite for the Weddell Sea region based on geostrophic estimates from steric height anomaly contours from Plate 56 in Olbers and others (1992), from 1992 Ice Station Weddell (ISW) current measurements, and from subjective interpretation (Geiger, 1996). A temporally varying mixedlayer depth was generated using sinusoidal interpolation between $20 \mathrm{~m}$ on 1 February and $100 \mathrm{~m}$ on 1 August based on measurements from Gordon and Huber (1990). For oceanic heat fluxes, estimates from ISW measurements (Lytle and Ackley, 1996) show about $7 \mathrm{~W} \mathrm{~m}^{-2}$ in the western Weddell Sea (about $60^{\circ} \mathrm{W}-40^{\circ} \mathrm{W}$ ) in winter. From Gordon and Huber (1990) a winter heat flux value below the ice of about $37 \mathrm{~W} \mathrm{~m}^{-2}$ is estimated for the eastern Weddell (about $20^{\circ} \mathrm{W}-10^{\circ} \mathrm{E}$ ). In the summer, an average value of about $2 \mathrm{~W} \mathrm{~m}^{-2}$ for the entire region is typical (Parkinson and Washington, 1979). Using these values, with linear interpolation between $40^{\circ} \mathrm{W}$ and $20^{\circ} \mathrm{W}$, we generated a longitudinal heat-flux distribution. Local temporal variations between summer and winter values were then used with the same sinusoidal interpolation method as for the mixed-layer depth. Relative humidity is based on climatological 30 year monthly mean surface dewpoint and air temperature from Taljaard and others (1969).

The three forcing parameters (air temperature, ocean heat flux and relative humidity) examined in this paper are input variables to the surface heat budget equation used to compute growth:

$$
0=(1-A) F_{\mathrm{sw}}+F_{\mathrm{lw}}+F_{\mathrm{sh}}+F_{\mathrm{lh}}-F_{\mathrm{bb}}+F_{\text {ice }}-F_{\text {ocean }}
$$

where

$$
\begin{aligned}
F_{\mathrm{sw}}= & Q\left(1-0.6 C^{3}\right) \\
F_{\mathrm{lw}}= & D_{3} T_{\mathrm{a}}^{4}\left\{1-0.261 \exp \left(-7.77 \times 10^{-4}\left(273-T_{\mathrm{a}}\right)^{2}\right\}\right. \\
& \times(1+0.275 C) \\
F_{\mathrm{sh}}= & D_{1}\left|\mathbf{V}_{\mathrm{a}}\right|\left(T_{\mathrm{a}}-T_{\mathrm{i}}\right) \\
F_{\mathrm{lh}}= & D_{2}\left|\mathbf{V}_{\mathrm{a}}\right|\left(R H q_{\mathrm{a}}\left[T_{\mathrm{a}}\right]-q_{\mathrm{i}}\left[T_{\mathrm{i}}\right]\right) \\
F_{\mathrm{bb}}= & D_{3} T_{\mathrm{i}}^{4} \\
F_{\text {ice }}= & \frac{K}{H}\left(T_{\mathrm{w}}-T_{\mathrm{i}}\right)
\end{aligned}
$$

$A$ is the albedo and $C$ is the fractional cloud cover; $F_{\mathrm{sw}}$ and $F_{\text {lw }}$ are the shortwave and longwave radiation terms; $F_{\text {sh }}$ and $F_{\mathrm{lh}}$ are the sensible and latent heat fluxes; $F_{\mathrm{bb}}$ is black- body radiation emitted from the ice and open water areas; $F_{\text {ice }}$ is the conductive heat flux through the ice; $F_{\text {ocean }}$ is the specified oceanic heat flux; $T$ is temperature $(\mathrm{K}) ; q$ is the specific humidity; and $\mathbf{V}$ is velocity with subscripts a, i, and $\mathrm{w}$ specifying air, ice and water values, respectively. Terms in square brackets are the arguments to the functions specified to their left. In areas of open water, the mixedlayer temperature replaces the ice temperature. Coefficients $D_{1}$ and $D_{2}$ are respectively the bulk sensible and latent heat transfer coefficients; $D_{3}$ is the Stefan-Boltzmann constant times the surface emissivity; $K$ is the ice conductivity; $H$ is the ice thickness; and $R H$ is the relative humidity. $Q$ is the time-averaged local radiation flux defined by:

$$
\begin{aligned}
Q= & \frac{S_{0} E_{0}}{t_{2}-t_{1}} \int_{t_{1}}^{t_{2}} \\
& \frac{(\cos Z)^{2}}{1.085 \cos Z+(2.7+\cos Z) e a \times 10^{-5}+0.1} d t
\end{aligned}
$$

$\cos Z=\sin \varphi \sin \delta+\cos \varphi \cos \delta \cos H A$

$S_{0}$ is the solar constant equal to $1353 \mathrm{~W} \mathrm{~m}^{-2} ; E_{0}$ the eccentricity correction given in Equation (1.2.1) in Iqbal (1983); $\varphi$ is latitude and $\delta$ is the declination in degrees as given in Equation (1.3.1) in Iqbal (1983). H A is hour angle $\left(15^{\circ}\right.$ times noonlocal apparent time) and $e a$ is the vapor pressure. Monthly average cloud cover is interpolated from figure 9 in Parkinson and Washington (1979). This budget is the same as that used in Hibler (1980) and is further described in Geiger (1996) and Parkinson and Washington (1979).

\section{RESPONSE AND SENSITIVITY TO AIR TEMPERATURE}

Thermal contributions to the expansion and decay of sea ice depend on the freezing and melting points of sea ice, which are not the same. Sea ice freezes with the onset of winter at sea-water freezing point, depending on salinity, around $-2^{\circ} \mathrm{C}$ or $271 \mathrm{~K}$ (Weeks and Ackley, 1986). During the winter season, ice undergoes a continuous leaching process expelling salt from the ice, so that by spring melt, the ice thaws at a temperature closer to $0^{\circ} \mathrm{C}$ or about $273 \mathrm{~K}$, which is the melting point of fresh-water ice (Weeks and Ackley, 1986). This phase-change temperature dependence significantly affects the relation of air temperature to the annual decay and expansion of sea ice. We examine this dependence and the response of the ice edge to different temperature scenarios by looking at temporal changes in ice thickness and air temperature along a $28^{\circ} \mathrm{W}$ north-south transect.

The case of atmospheric-only input (no ocean current or heat flux and a constant $60 \mathrm{~m}$ mixed-layer depth) using the original ECMWF temperature field, is shown in the middle panel of Figure 1 for the 1992 annual cycle at 6 hour time intervals. The two cases of a $2 \mathrm{~K}$ air-temperature increase (Fig. 1, upper panel) and decrease (Fig. 1, lower panel) are also shown. Monthly averaged air-temperature contours of $271 \mathrm{~K}$ (the freezing point of sea ice) and $273 \mathrm{~K}$ (the melting point of fresh water) are the dotted and dashed lines, respectively,

Beginning with the original ECMWF air-temperature fields (middle panel), an ice-edge decay and expansion emerges with an annual cycle offset (phase shifted) from the annual cycle in air temperature. The delay of ice expansion is partially due to the thermal inertia of the mixed 


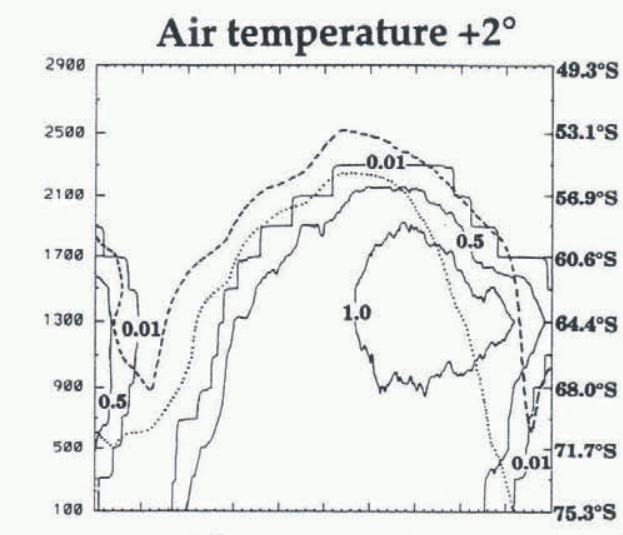

Air temperature

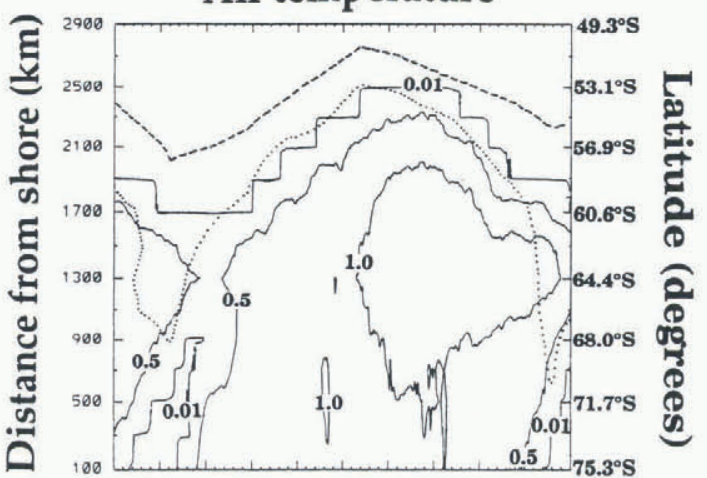

Air temperature $-2^{\circ}$

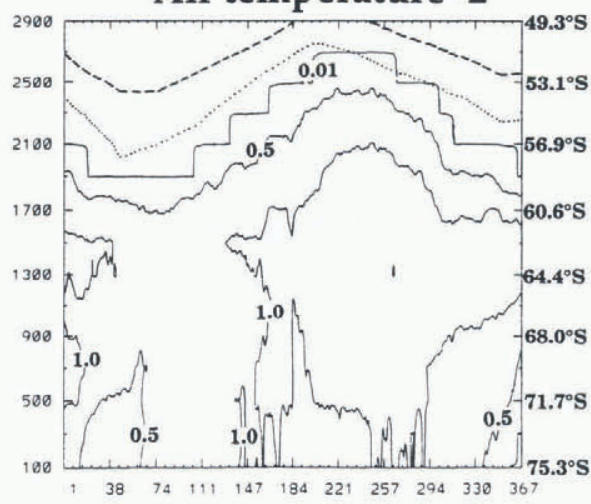

Time (days)

\section{- - - Air temp. at melting point of fresh-water ice Air temp. at freezing point of sea-water ice}

Fig. 1. Ice-thickness sensitivity to air temperature along a $28^{\circ} \mathrm{W}$ transect using 6 hour interval ECMWF atmospheric input fields, both unaltered (middle panel) and modified by $\pm 2 K$ (upper and lower panels). Solid contours are $m$ of ice thickness: the dotted $271 \mathrm{~K}$ (ice freezing) air temperature; the dashed $273 \mathrm{~K}$ (ice melting) air temperature.

layer. During expansion, the ice edge is south of the freezing line, while during the decay, the ice edge lies between the air-temperature lines where ice melts and freezes, with airtemperature changes preceding the ice response. The transect is located in a region that becomes ice free along the coast in February (see the presence of the $0.01 \mathrm{~m}$ contour along the coast between days 10 and 45 in the middle panel).

If air temperature is increased uniformly in both space and time by $2 \mathrm{~K}$ (Fig. 1, upper panel), the location of the $271 \mathrm{~K}$ air-temperature contour from the original dataset instead becomes the $273 \mathrm{~K}$ air temperature contour. A consequent reduction of $200 \mathrm{~km}$ in the maximum extent of sea ice in winter occurs. Open water along the coast, combined with increased global air temperature, also completely eliminates ice along this transect for all of February (days $31-60$ ). This meltback occurs in a location that had a minimum ice extent of $800 \mathrm{~km}$ (900-1700 km from the shore) under standard atmospheric conditions (middle panel). Decreasing the air temperature by $2 \mathrm{~K}$ (Fig. 1, lower panel) uniformly in space and time extends the ice edge about $200 \mathrm{~km}$ further north than for the standard atmospheric dataset, and removes the presence of open water in summer along the coast. The summer minimum extent during the decreased-temperature case similarly is increased by about $200 \mathrm{~km}$. These cases illustrate that the ice responds linearly in maximum ice extent relative to air-temperature change. Additionally, the summer meltback is particularly sensitive to combined feedback responses between air temperature and local dynamics, and has a positive feedback response to temperature changes near the melting point, as occur during that period.

Air temperature plays a role at the onset of the decay process by reducing ice thickness. This initial process sets off a series of thermodynamic and dynamic processes. Airtemperature increases contribute to heat storage in the mixed layer, and hence the oceanic dynamics. The combined ocean and atmospheric conditions then work together to melt the ice to form open water, which then changes the albedo. Additional feedbacks to the atmosphere, not considered here, can then also follow. For example, thermal atmospheric changes could induce atmospheric pressure changes and hence wind changes, thereby creating or destroying leads and redistributing the compactness and thickness of the sea-ice field. Since most of the Southern Ocean is covered with relatively thin ice, particularly along its wide outer margin (300-1000 km in extent from the shore), the albedo changes are particularly extensive. In the Arctic, an analogous process involving melt pond formation in much thicker ice, with increasing temperatures, is followed by feedback radiative heating. Since melt ponds do not exist in the Antarctic (due to its lower relative humidity; Andreas and Ackley, 1982), the analogue of the Arctic melt pond is the extensive melt-back of thinner ice $(<0.5 \mathrm{~m})$ in the Antarctic that proceeds directly to open water. Radiative heating processes, in turn, impact dynamics, thermodynamics and the albedo from which a feedback loop ensues. Hence, air temperature acts as an activator in both the melt-back process and ice-expansion processes.

\section{OGEAN HEAT FLUX SENSITIVITY}

Examples of the two dimensional (2-D) distribution of 7 day average ice thickness are shown in Figure 2. An atmospheric-only case (Fig. 2, left panels), with no ocean heat flux or ocean current and a $60 \mathrm{~m}$ fixed mixed layer, shows modeled ice exceeding the observed 7 day composite ice edge to the northeast in March, and in general everywhere during the maximum extent in August. For the standard model (Fig. 2, right panels) including ocean heat flux, geostrophic current and a variable mixed-layer depth, a similar ice-edge extent during the maximum in August is seen, but there is less extent of ice in March, more closely corresponding to the observed ice edge. There is also an overall thinner ice-thickness distribution. A sensitivity study examining the response of the ice to ocean heat flux (Fig. 3), clarifies this response. A small amount of uniform ocean heat flux $\left(2 \mathrm{~W} \mathrm{~m}^{2}\right)$, has negligible impact on the ice edge vs the 

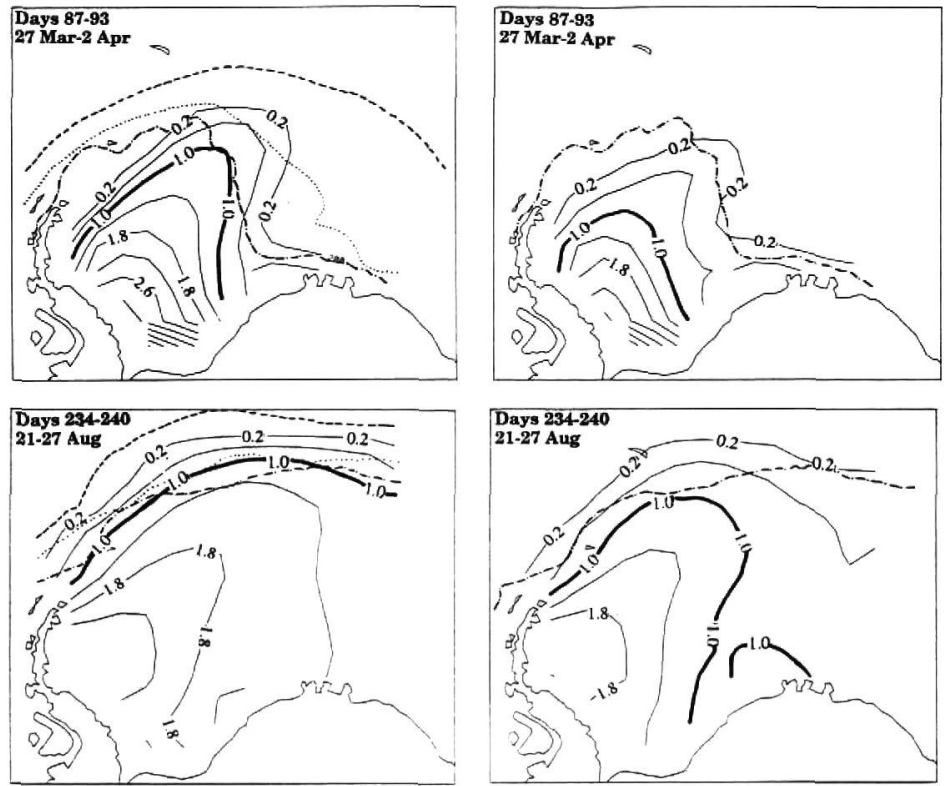

\title{
- - - Air temp. at melting point of fresh-water ice Air temp. at freezing point of sea-water ice Seven day composite observed ice edge
}

\begin{abstract}
Fig. 2. The 2-D $200 \mathrm{~km}$ resolution sensitivity study for the 1992 annual sea-ice cycle in the lteddell Sea. Atmospheric-onty forring is in the left panels ( no ocean heal flus or current and constant $60 \mathrm{~m}$ mixed-laver depth). The standard case is in the right panels 16 hour interal wimd and air lemperatuse, monshty mean dimalolog iral splative humidity and geostrophic curvent, seasonalty varying

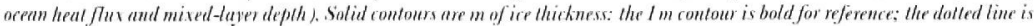
the $27 \mathrm{~K}$ (ice freesing) air temperature; the dashed line is the $273 \mathrm{~K}$ (ice melling) air lemperature; the dash-dot line is the ISIDC abseried l992 ice edge.
\end{abstract}

atmospheric-only case, but a slight impact on the ice-thickness distribution during both minimum and maximum extent (e.g. comparing the location of the 1.0$) \mathrm{m}$ and $1.8 \mathrm{~m}$ contours). Comparatively, the minimum ice-edge extent with a tenfold increase in ocean heat llux $20 \mathrm{~W} \mathrm{~m}^{2}$, right panels in Fig. 3) is obviously further south in March at the onset of ire growtly, while the ice edge is similar to the atmosphericonly case during the winter maximum. In terms of oceanic heat processes, lhe oceanic heat flux therefore works in conjunction will the mixed-layer heat storage to reduce the ice thickness.

During the maximum extent period, the ice-edge extent changes little with occan heat flux compared to atmospheric-only forcing. while the interior ice thickness becomes uniformly thinner everywhere during both minimum and maximum extent. In the summer, the oceanic heat flux is sufficient despite being very low $\left(2 \mathrm{~W} \mathrm{~m}^{2}\right)$ to reduce ihe extent of the ice edge where the ice is thin (e.g. March in Fig. 2). The ice-thickness distribution, particularly thin ice. is therefore much more sensitive to ocean heat flux than is the ice-edge winter advance and retreat e.g. $0.2 \mathrm{~m}$ and $1.0 \mathrm{~m}$ thickness contours in Figs 2 and 3). With the variable heat flux in the standard case as described earlicr, the castrrn part of the Weddell Sea ice pack rellects results of the higher oceanic heat flux case, while the western part reflects results from the lower heat flux case shown in Figure 3.

\section{RELATIVE HUMIDITY SENSITIVITY}

Initial runs were made assuming constant relative humidity values for both low $40 \%$ ) and high $190 \%$ values, as seen in Figure 4. L'sing otherwise standard atmospheric and oceanic inpu lields, these produced unrealistic ice-extent results. While a lower relative humidity simulation seems to produce a reasonable ice extent along the coast of the Antarctic Peninsula, it overshoots the observed ice edge elsewhere, especially for the winter months. Contrary to this, a high humidity case $(90 \%)$ is reasonable in reproducing the observed ice edge during winter months, but excessively reduces the ice in the summer months. Humidities were not available from the EC:MWF fields used for the atmospheric forcing, so a spatially variable relative humidity lield, rather than a constant one, was derived using the dewpoint and air temperatures from the climatological 30 year monthly mean data of Taljaard and others 1969 . Using this information, a monthly average regional distribution of relative humidity was computed, linearly interpolated to 6 hour in- 

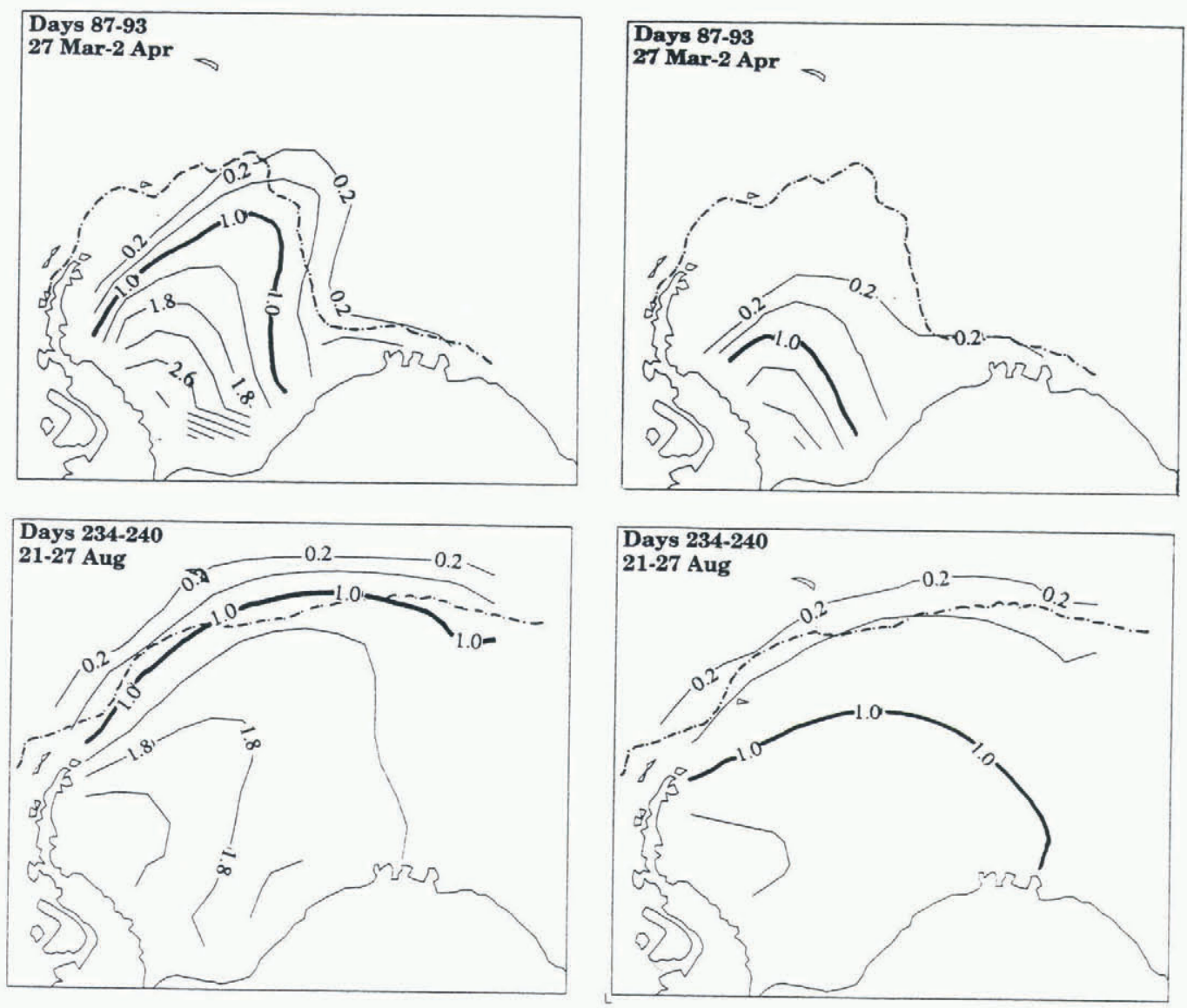

Fig. 3. Ice-thickness sensitivity to low (2 $\mathrm{W} \mathrm{m}^{-2}$ in the left panels) and high (20 $\mathrm{W} \mathrm{m}^{-2}$ in the right panels) constant ocean heat flux for the 2-D-200 km resolution case. The dash-dot line is the NSIDC observed 7 day composite ice edge from the same 7 day period as the model; the solid contours are $m$ of ice thickness.
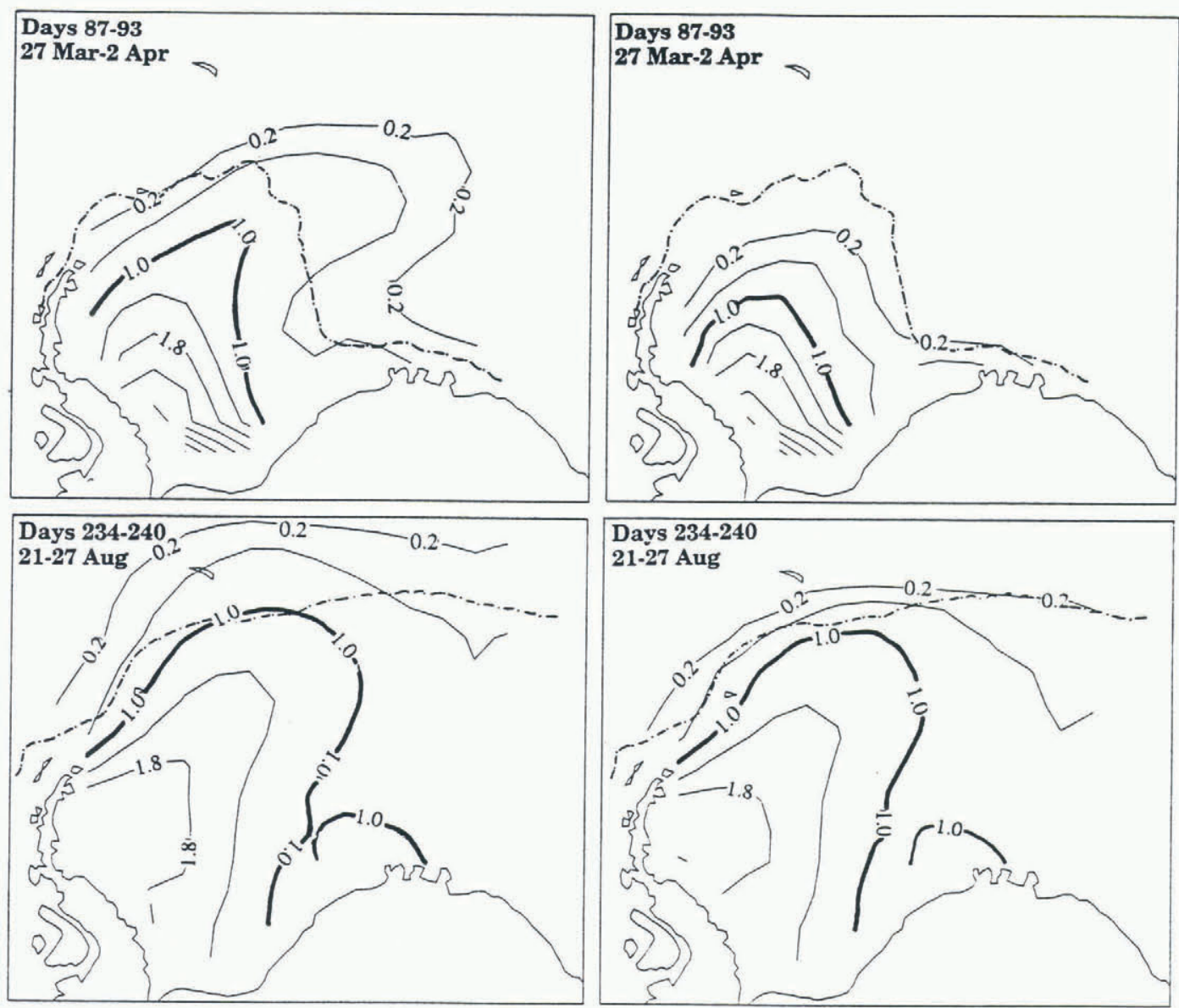

Fig. 4. The 2-D model output for two different cases of constant relative humidity and otherwise standard atmospheric and oceanic input fields. The left and right panels show cases of relative humidity $(\mathrm{RH})$ at 40 and $90 \%$, respectively. The dash-dot line is the NSIDC observed 7 day composite ice edge from the same 7 day period as the model; solid contours are m of ice thickness. 
terval input fields, and then used in the heat budget for the standard run (Fig. 2, right panel).

To understand this response further, we examine ice growth sensitivity to relative humidity $(R H)$ as it affects the latent heat (Equation (5)). We can rewrite Equation (5) as:

$$
F_{\mathrm{lh}} \approx D_{2}\left|\mathbf{V}_{2}\right| q(R H-1) .
$$

The approximation comes about because, in this form, the formula for $q_{\mathrm{a}}$ and $q_{\mathrm{i}}$ is the same except for their respective temperatures such that $q_{\mathrm{a}} \approx q_{\mathrm{i}} \approx q$ for relatively small differences between air temperature and surface ice temperature. For $R H$ close to 1 , this yields a small latent heat flux relative to the sensible heat flux because $(R H-1)$ approaches zero. Conversely, as $R H$ decreases, $(R H-1)$ becomes an increasingly more negative number and the latent heat magnitude increases.

Since the sensible heat flux is unaffected by $R H$, the change in latent heat is responsible for the ice growing rapidly at lower relative humidities and slowly at higher humidities. A smaller $R H$ in regions of sub-freezing temperatures therefore results in more ice growth. Furthermore, the sensitivity results show that the ice-thickness distribution in the interior of the pack during winter (August in Fig. 4 ) is only marginally different at $40 \%$ vs $90 \% R H$ for thicknesses of $1.0 \mathrm{~m}$ or more, but the ice edge and thinner ice $(<0.67$

$1 \mathrm{~m}$ ) are much further north in the $R H=40 \%$ case. Therefore, it is the thin ice and open water during the advance, and the thin ice during the decay, which are being impacted by the relative humidity in the annual cycle.

Along the dry continent of Antarctica relative humidity is low, while moist air of marine origin is located closer to the ice edge. Because of the presence of a dry central continent in the Antarctic region, the seasonal sea-ice cycle is subjected to a greater range of humidity than the Arctic, which is typically close to $90 \%$ relative humidity year round. The presence of melt ponds in the summer in the Arctic vs a lack of melt ponds in the Antarctic (Andreas and Ackley, 1982) further substantiates the lower humidity seen in the western Weddell Sea relative to the Arctic. Hence the need for high-quality humidity data in input fields is more critical for sea-ice modeling in the Antarctic than in the Arctic.

A test to illustrate this effect is shown in Figure 5 using the standard model. Climatological monthly average relative humidity at the tip of the Antarctic Peninsula ranges from $80 \%$ to $>90 \%$. Also in this region, the standard model poorly predicts the northward ice margin near the Peninsula coast during the summer months (Fig, 2, right panel), a difficulty not atypical of ice models in the Weddell Sea (Hibler and Ackley, 1983). By reducing the humidity near the continent to $40 \%$ (boxed area in Fig. 5) we obtain an increase in ice growth in summer along the Peninsula compared to the standard run (Fig. 2), producing an ice edge closer to the observed. Increasing the local northward ocean current along the Antarctic Peninsula (by $7 \mathrm{~cm} \mathrm{~s}^{-1}$ ) is also capable of increasing the northern extent of the ice growth there (Geiger, 1996). While the humidity may not be the only reason for the lack of good correlation in summer months between models and observed ice at the northern tip of the Peninsula, it is a likely candidate to explain the discrepancy.
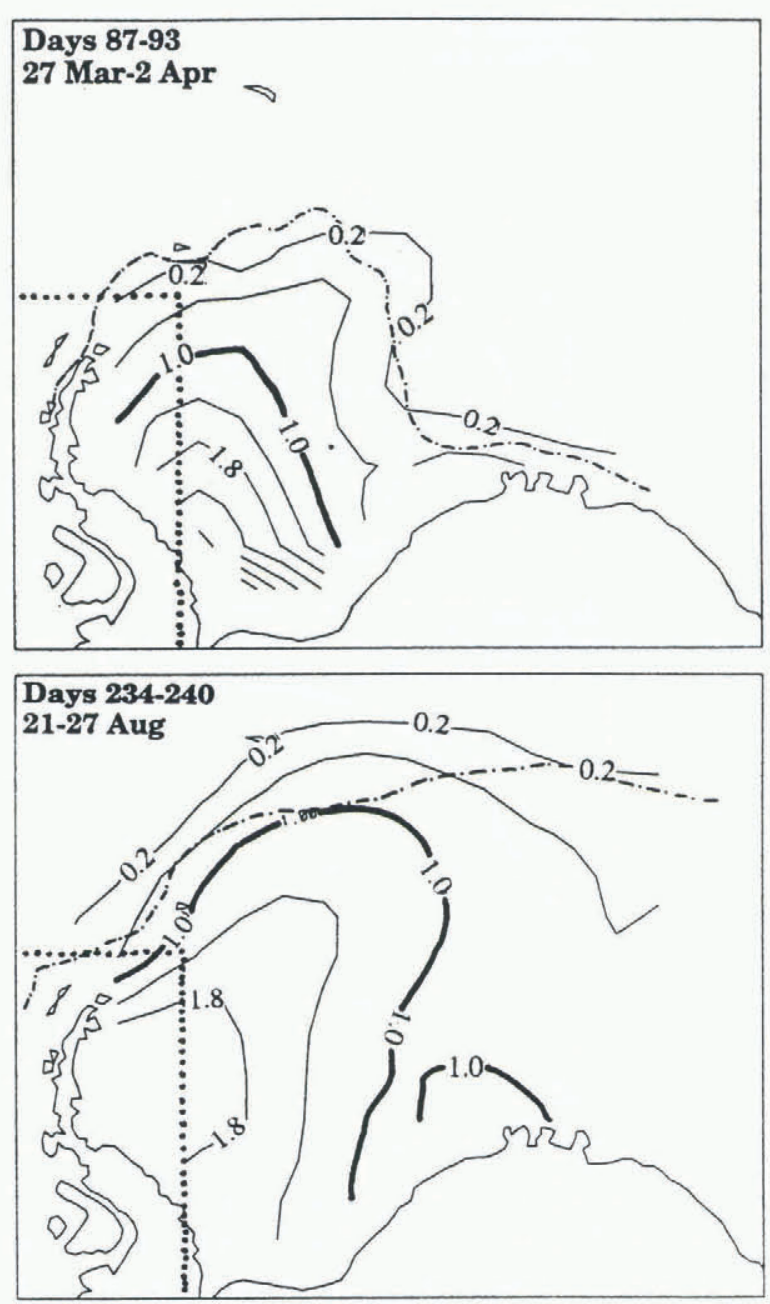

Fig. 5. The 2-D model sensitivity to low relative humidity along the Antarctic Peninsula. Model inputs are the same as the standard case except for constant low humidity ( $R H=40 \%)$ in the dotted box area. The solid contours are $m$ of ice thickness; dash-dot line is the NSIDC observed 7 day composite ice edge.

\section{DISGUSSION AND SUMMARY}

Ice-edge and ice-thickness distribution were used to determine responses and relative differences caused by the specific thermal input variables of air temperature, ocean heat flux and relative humidity. Air temperature dominates iceedge extent during the winter months. The difference in ocean heat flux values between the eastern and western areas of the Weddell Sea indicate that minimum ice extent and overall thickness were both reduced by increased ocean heat flux with responses in the eastern Weddell Sea being particularly sensitive to the high heat fluxes currently observed there. Later stages of ice-edge retreat and earlier stages of expansion (summer months) are sensitive to relative humidity, which affects the latent heat flux. Because of the presence or absence of the cold dry air along the Antarctic Peninsula, relative humidity sensitivity was most noticeable there, such that the case with an imposed $R H=40 \%$ along the coast produced the best results compared to observed ice-edge composites.

In terms of sea-ice response to climate changes, increases and decreases in mean air temperature can significantly affect the ice-edge extent. In this respect, air temperature acts as an activator for the seasonal meltback by precondi- 
tioning the system such that albedo feedback, radiative heat transfer and dynamic processes begin once significant amounts of open water form. Events that increase ocean heat flux will reduce the overall ice-thickness distribution, but have little effect on the maximum ice-edge extent during the winter months. It will, however, be very difficult to detect these ice-thickness changes using remote sensing unless the ice becomes critically thin, and an overall catastrophic melt-back occurs. On the other hand, if increased atmospheric temperatures also lead to an overall increase in atmospheric moisture, the latent heat transfer from air to ice, as well as the sensible heat, will be altered. In this scenario ice-edge extent would be changed considerably, and would probably be readily detectable by current satellite monitoring methods. These findings emphasize the need for comparison of both ice-edge location and interior icethickness distribution in model validation. The ice-thickness distribution is the more critical and sensitive variable to variations in oceanic forcing, while ice extent responds more directly to atmospheric forcing changes.

\section{ACKNOWLEDGEMENTS}

This work was made possible by grants from the NSF (No. OPP-9024809 and DPP-9203470) and ONR (No.N0014-931-1221). Our thanks to ECMWF for the analysis fields made available by C. Kottmeier (AWI) in Bremerhaven, Germany, to C. Hanson at NSIDC who provided the NavyNOAA NIC ice edge information, and J. Waugh for technical support at the Thayer School of Engineering.

\section{REFERENCES}

Andreas, E. L. and S. F. Ackley. 1982. On the differences in ablation seasons of Arctic and Antarctic sea ice. 7. Atmos. Sci, 39 (2), 440-447.

Geiger, C. A. 1996. Investigation of dynamic sea ice processes in the Weddell Sea during 1992. (Ph.D. thesis, Dartmouth College. Thayer School of Engineering.)

Gordon, A. and B. A. Huber. 1990. Southern Ocean winter mixed layer. $\mathcal{f}$. Geophys. Res., 95 (C7), 11,655-11,672.
Hibler, W. D., III. 1979. A dynamic thermodynamic sea ice model. 7. Phys. Oceanogr., 9 (7), 815-846.

Hibler, W. D., III. 1980. Modeling a variable thickness sea ice cover. Mon. Weather Rev., 108 (12), 1943-1973.

Hibler, W. D., III and S. F. Ackley. 1983. Numerical simulation of the Weddell Sea pack ice. 7. Geophys. Res., 88 (C5), 2873-2887.

Hibler, W. D., III and C. F. Ip. 1995. The effect of sea ice rheology on Arctic buoy drift. In Dempsey, J. P. and Y. D. S. Rajapakse, eds. Ice mechanics1995. Vol. AMD- 207. New York, American Society of Mechanical Engineers. Applied Mechanics Division, 255-263.

Ip, C. F. 1993. Numerical investigations of different rheologies on sea-ice dynamics. (Ph.D. thesis, Dartmouth College.)

Iqbal, M. 1983. Sun Earth astronomical relationships. In Iqbal, M., ed. An introduction to solar radiation. New York, Academic Press, 1-28.

Koch, C. 1988. A coupled sea ice atmospheric boundary model. Part I. Decription of the model and 1979 standard run. Beitr. Phys. Atmos. $61(4), 344-354$.

Lemke, P., W. B. Owens and W. D. Hibler, III. 1990. A coupled sea icemixed layer-pycnocline model for the Weddell Sea. 7. Geophys. Res., 95 C6), 95139525

Lytle, V. I. and S. F. Ackley. 1996. Heat flux through sea ice in the western Weddell Sea: convective and conductive transfer processes. 7. Geophys. Res., 101 (C4), 8853 - 8868.

Olbers, D., V. Gouretski, G. Seiss and J. Schroter. 1992. Hydrographic allas of the Southern Ocean. Bremerhaven, Alfred-Wegener-Institute.

Owens, W. B. and P. Lemke. 1990. Sensitivity studies with a sea ice-mixed layer-pycnocline model in the Weddell Sea. f. Geophys. Res., 95 (C6), 9527-9538.

Parkinson, C. L. and W. M. Washington. 1979. A large-scale numerical model of sea ice. J. Geophys. Res., 84 (Cl), $311-337$.

Stössel, A., P. Lemke and W. B. Owens. 1990. Coupled sea ice mixed layer simulations for the Southern Ocean. J. Geophys. Res., 95 (C6), 95399555.

Taljaard, J. J., H. van Loon, H. L. Crutcher and R. L. Jenne. 1969. Climate of the upper air. I. Southern Hemisphere. Vol. I. Temperature, dew points, and heights at selected pressure levels. Washington, DC, U.S. Navy. Weather Service Command. (NAVAIR Report 50-1C-55.)

Weeks, W. F. and S. F. Ackley. 1986. The growth, structure, and properties of sea ice. In Untersteiner, N., ed. Geophysics of sea ice. London, ete., Plenum Press, 9-164. (NATO ASI Series B: Physics 146.

Ypersele, J. P.van. 1986. A numerical study of the response of the Southern Ocean and its sea ice to a $\mathrm{CO}_{2}$-induced atmospheric warming. (Ph.D. thesis, Université Catholique de Louvain.)

Zhang, J. and W. D. Hibler III. In press. On an efficient numerical method for modeling sea ice dynamics. J. Geophys. Res.

Zwally, H.J., J. C. Comiso, C. L. Parkinson, W. J. Campbell, F. D. Carsey and P. Gloersen. 1983. Antarctic sea ice, 1973-1976: satellite passive-microwave observations. Washington, DC, National Aeronautics and Space Administration. (NASA SP-459.) 